Rici Desriana Putri, Habullah Malaul Partisipasi Masyarakat Nagari dalam Meningkatkan Pembangunan Sarana dan Prasarana Nagari di Nagari Ladang Panjang Kabupaten Pasaman

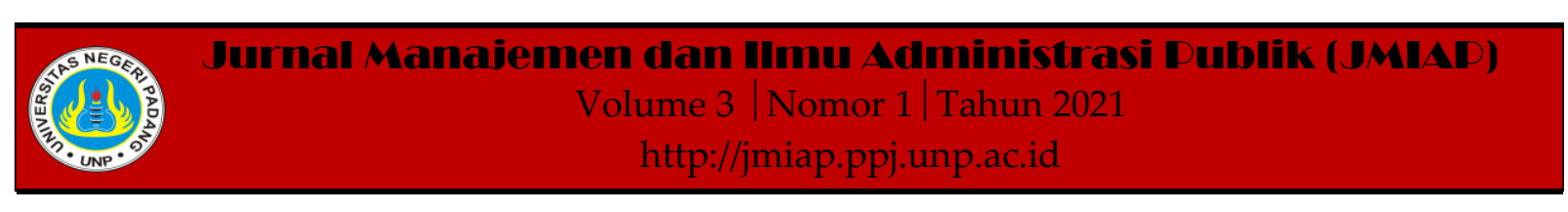

\title{
PARTISIPASI MASYARAKAT NAGARI DALAM MENINGKATKAN PEMBANGUNAN SARANA DAN PRASARANA NAGARI DI NAGARI LADANG PANJANG KABUPATEN PASAMAN
}

\author{
Rici Desriana Putri ${ }^{1(a)}$, Habullah Malau ${ }^{2(b)}$ \\ ${ }^{1}$ Jurusan Ilmu Administrasi Negara, Universitas Negeri Padang \\ ${ }^{2}$ Jurusan Ilmu Administrasi Negara, Universitas Negeri Padang \\ ${ }^{a)}$ ricidesriana19@gmail.com, ${ }^{b}$ hasbullahmalau4@gmail.com
}

\begin{abstract}
This study aims to determine community participation in the development of village facilities and infrastructure in Nagari Ladang Panjang, Pasaman Regency. This community partipation is seen from how the community responds to conditions in the long field area, such as community participation in the development of village facilities and infrastructure. The research method used in this study is a qualitative descriptive research method that describes phenomena that actually occur in the field. The data source obtained through the interview process with informants and documents related to research. Data collection techniques are by means of observation, documentation and interviews. The data analysis technique used is an interactive analysis technique which consists of three components, namely data reduction, data presentation, and conclusion drawing. The results showed that community participation in the development of village facilities and infrastructure in Nagari Ladang Panjang was still lacking. In the construction of the new village guardian's office, for example, the community was reluctant to give away their land for free, even though in the end the village was able to convince the community to donate their land to build a new Nagari guardian office. In addition, not many people are willing to attend the deliberations for village development organized by the nagari government, this indicates a lack of public awareness or participation in village development in Nagari Ladang Panjang. Therefore, there is a need for approaches and counseling by the village government to the community on the importance of community participation in village development in Nagari Ladang Panjang.
\end{abstract}

Keywords : Participation, Community, Development, Nagari Ladang Panjang

Corresponding author. Email. ricidesriana19@gmail.com

How to cite this article. Putri, R. Desriana \& Malau, H. (2021). Partisipasi Masyarakat Nagari dalam Meningkatkan Pembangunan Sarana dan Prasarana Nagari di Nagari Ladang Panjang Kabupaten Pasaman. Jurnal Manajemen dan Ilmu Administrasi Publik (JMIAP) Jurusan Ilmu Administrasi Negara Fakultas Ilmu Sosial Universitas Negeri Padang, Volume 3 (1), Hal. 56-62.

http://jmiap.ppj.unp.ac.id

Copyright $\odot 2021$. Published by Labor Jurusan Ilmu Administrasi Negara FIS UNP, Padang

56 | Jurnal Manajemen dan Ilmu Administrasi Publik | Volume 3 | Nomor 1 | Tahun 2021 | (Hal. 56-62) 
Rici Desriana Putri, Habullah Malau| Partisipasi Masyarakat Nagari dalam Meningkatkan Pembangunan Sarana dan Prasarana Nagari di Nagari Ladang Panjang Kabupaten Pasaman

\section{PENDAHULUAN}

Pembangunan daerah adalah suatu upaya perubahan berkelanjutan yang telah direncanakan secara sadar dengan tujuan yang lebih bernilai dan lebih baik. Pembangunan dapat terlaksanakan secara efektif apabila ada partisipasi masyarakat di dalamnya. Menurut (Mustanir \& Lubis, 2017) partisipasi masyarakat itu merupakan modal utama keberhasilan pembangunan. Lebih lanjutnya partisipasi masyarakat mengimbangi kelemahan pemerintah dalam masalah pembangunan daerah. Dalam Perda Kabupaten Pasaman Nomor 10 Tahun 2007 juga menyatakan bahwa pemerintahan nagari mempunyai kewajiban untuk membangun daerahnya yang dibantu oleh masyarakat untuk mewujudkan kesejahteraan masyarakat itu sendiri.

Kesadaran warga atau masyarakat terhadap minat dan strategi yang diterapkan untuk pelaksanaan program pembangunan nagari merupakan salah satu bentuk dari partisipasi masyarakat.

Sebagai objek dalam keikutsertaan masyarakat atau warga dalam pembangunan daerahnya saat ini tentulah bukan hanya itu saja, melainkan juga sebagai subjek dari pembangunan yang dilakukan. Agar pembangunan berjalan sebagaimana yang diharapakan, maka prinsip pembangunan nagari menegaskan bahwa yang menjadi pelaku utama dalam pembangunan yaitu adalah masyarakatnya sendiri. Oleh karena itu besar pengaruh dari partisipasi masyarakat untuk pembangunan di daerahnya, karena keberhasilan dari suatu program yang telah direncanakan tidak akan berjalan dengan baik jika tidak adnya partisipasi dari masyarakat.

Nagari Ladang Panjang, Kecamatan Tigo Nagari, Kabupaten Pasaman Nagari Ladang Panjang Kecamatan Tigo Nagari Kabupaten Pasaman misalnya, pembangunan pada nagari dilakukan dengan melibatkan partisipasi masyarakat. Sedangkan untuk lembaga-lembaga nagari lainnya ikut serta mengawasi dan mengevaluasi terhadap pekerjaan yang di laksanakan oleh pemerintah nagari, seperti BAMUS, KAN, LPMN, PLD dan lain-lain. Namun, partisipasi masyarakat di Nagari Ladang Panjang sangat kurang. Seperti yang dijelaskan oleh Bapak Jama selaku Kaur Perencanaan Pembangunan Sarana dan Prasarana di Nagari Ladang Panjang, sebagai berikut:

"Partisipasi masyarakat disini memang kurang menurut saya selaku kaur perencanaan, karena kami meminta adanya partisipasi atau sumbangan dari masyarakat tetapi ada masyarakat yang masih lengah tentang hal yang kami beritahukan. Contohnya saja untuk pembangunan mereka harus menyumbang pasir, semen atau kebutuhan lainnya tetapi himbauan yang kami berikan hanya di anggap tidak penting. Apalagi untuk pembuatan kantor wali nagari yang baru, kami sebagai perangkat sangat membutuhkan lahan yang dimana penentu utama untuk diajukan, tetapi tidak adarespon dari masyarakat". (Wawancara 07 September 2020).

Asumsi para pakar dalam mencapai suatu keberhasilan untuk pembangunan adalah tingkat kepedulian masyarakat atau partisipasi masyarakat dalam proses perencanaan pembangunan. Karena semakin tinggi partisipasi dari masyarakat, maka output yang dihasilkan akan lebih optimal, dengan kata lain semakin tinggi pula tingkat keberhasilan dari pembangunan yang akan dicapai di daerahnya.

Oleh sebab itu, penulis tertarik untuk melalukan penelitian terhadap permasalahan tersebut yaitu bagaimana tingkat partisipasi masyarakat nagari dalam meningkatkan pembangunan sarana dan prasarana nagari di Nagari Ladang Panjang.

\section{TINJAUAN PUSTAKA \\ Pengertian Partisipasi}

Partisipasi adalah peran serta masyarakat secara sukarela dan tanpa paksaan dalam suatu kegiatan. Parisipasi disebut juga sebagai upaya untuk memampukan masyarakat untuk dapat menolong diri 
Rici Desriana Putri, Habullah Malau| Partisipasi Masyarakat Nagari dalam Meningkatkan Pembangunan Sarana dan Prasarana Nagari di Nagari Ladang Panjang Kabupaten Pasaman

mereka sendiri, dimana partisipasi ini hasilnya dinikmati oleh masyarakat, dikelola oleh masyarakat serta berasal dari masyarakatitu sendiri. Partisipasi yang dimaksud adalah tidak hanya dalam bentuk materi tapi juga bisa berupa partisipasi pikiran dan tenaga.

Menurut Sumardi dalam Rizal Andreeyan dalam e-juornal Administrasi Negara vol. 2 no.4 (2014:1940), mengatakan bahwa partisipasi berarti peran serta seseorang atau kelompok masyarakat dalam proses pembangunan baik dalam bentuk pertanyaan maupun dalam bentuk kegiatan dengan memberi masukan, pikiran, tenaga, waktu, keahlian, modal dan materi serta ikut memanfaatkan menikmati hasil-hasil dari pembangunan.

\section{Partisipasi Masyarakat}

Partisipasi masyarakat diikut sertakan dalam berperan untuk setiap kegiatan mulai dari tahap pengidentifikasian, pelaksanaan, perencanaan, pengambilan keputusan, pengawasan dan evaluasi, hal ini merupakan tuntutan masyarakat untuk diberikan kesempatan dan diberdayakan. Ini bisa terjadi jika ada kesempatan, kemauan dan kemampuan dalam partisipasi masyarakat. Mengikutsertakan masyarakat untuk lebih bertanggung jawab dan cepat beradaptasi dengan segala perubahan yang terjadi.

Upaya dalam menumbuhkan partisipasi masyarakat menurut Islamy dalam (Malau, 2018) menyatakan bahwa kecenderungan pengembangan administrasi pembangunan ialah berorientasi untuk mendukung tata kelola dari pemerintahan yang menggabungkan local self-government fungsi selft-governing community dalam pembentukan pemerintahan desa.

\section{Pembangunan}

Menurut Keith Davis dalam Sastro Poetro (1998:16) bentuk partisipasi tersebut adalah sebagai berikut:

a) Konsultasi dalam bentuk jasa. b) Sumbangan spontan berupa uang atau barang.

c) Mendirikan proyek yang bersifat berdikari dan dibiayai oleh seluruh komuniti (biasanya diputuskan oleh rapat desa yang menentukan anggarannya).

d) Mendirikan proyek yang bersifat berdikari dan dananya berasal dari sumbangan individu atau instansi yang berasal dari luar lingkungan tertentu (dermawan atau pihak ketiga).

e) Sumbangan dalam bentuk kerja, biasanya dilakukan oleh tanaga ahli setempat.

f) Mengadakan pembangunan dikalangan keluarga desa sendiri.

Pembangunan (development) merupakan proses perubahan yang mencakup seluruh sistem sosial, seperti ekonomi, pertahanan, infrastruktur, politik, teknologi, pendidikan, kelembagaan dan budaya. (Alexander, 1994). Ide pokok dari pembangunan adalah sebagai berikut:
a) Pembangunan Wadah Pembinaan Bangsa
b) Pembangunan Mengarah pada Modernitas
c) Pembangunan Dilaksanakan Secara Sadar
d) Pembangunan Dilaksanakan Secara Terencana
e) Pembangunan merupakan Sebuah Proses

\section{Sarana dan Prasarana}

Segala sesuatu yang dapat dipakai sebagai alat dalam mencapai maksud atau tujuan, alat dan media disebut dengan sarana. Sedangkan prasarana adalah segala sesuatu yang merupakan penunjang utama terselenggaranya suatu proses (usaha, pembangunan, proyek dan sebagainya). (Nasional, 2007). Proses administrasi sarana dan prasarana:
a) Musyawarah perencanaan kebutuhan
b) Penyimpanan
c) Pengadaan dan pembentukan kebutuhan
d) Inventarisasi 
Rici Desriana Putri, Habullah Malaul Partisipasi Masyarakat Nagari dalam Meningkatkan Pembangunan Sarana dan Prasarana Nagari di Nagari Ladang Panjang Kabupaten Pasaman

e) Penyaluran

f) Rehabilitasi

g) Pemeliharaan

h) Pengendalian

i) Penghapusan dan penyingkiran

\section{Pemerintahan Nagari}

Kesatuan masyarakat hukum adat secara hidtoris dan geneologis, memiliki batasbatas dalam wilayah tertentu, serta memiliki harta kekayaan sendiri, berwenang memilih pemimpinnya secara musyawarah serta mengatur dan mengurus kepentingan masyarakat setempat disebut dengan pemerintahan nagari (Iskandar, 2009).

\section{METODE PENELITIAN}

Penelitian kualitatif merupakan jenis penelitian yang digunakan dalam penelitian ini. Penelitian kualitatif merupakan penelitian yang bertujuan untuk mendeskripsikan atau menggambarkan fakta-fakta yang ada secara sistematis tanpa memodifikasi gejala yang muncul berdasarkan fenomena yang terjadi di lapangan serta dari pengamatan fenomena tersebut. Penelitian ini dilakukan di Kabupaten Pasaman, Kecamatan Tigo Nagari, Nagari Ladang Panjang. Data sekunder dandata primer merupakan bentuk data yang diambil. Sedangkan teknik dan alat pengumpulan data yang digunakan diantaranya adalah: Observasi; Wawancara dan studi dokumentasi. Uji keabsahan data menggunakan teknik triangulasi sumber yang merupakan teknik yang digunakan peneliti dalam penelitian ini. Dengan membandingkan informasi atau data dari salah satu informan atau sumber data dengan informasi dari informan atau sumber data yang lain ialah cara melakukan triangulasi sumber. Teknik analisis data: Pengumpulan data; Reduksi Data; Penyajian Data dan Verifikasi dan Penarikan Kesimpulan.

\section{HASIL DAN PEMBAHASAN}

\section{Proses Pengambilan Keputusan}

Seperti yang di sampaikan oleh Bapak Jama selaku Kaur Perencanaan
Pembangunan kantor wali Nagari Ladang Panjang sebagai berikut:

“...Setiap proses pengambilan keputusan di Nagari Ladang Panjang termasuk pengambilan keputusan untuk sarana dan prasarana nagari dilakukan dengan mengadakan musyawarah nagari. Contohnya ketika pembangunan kantor wali nagari baru, hal itu kami peroleh setelah perangkat nagari melakukan rapat bersama masyarakat, yang sebelumnya dimana kantor wali nagari ini masih meminjam gedung serba guna milik nagari". (Wawancara 07 September 2020).

Namun, jika dilihat bahwa pada musrenbang nagari hanya sedikit masyarakat Nagari Ladang Panjang yang hadir pada saat rapat. Sebagaimana penjelasan dari Ibu Yanti Puspita sebagai berikut:

“......Kami selaku warga Nagari Ladang Panjang hanya mengikuti arahan dari jorong masing-masing, kalau memang adanya musyawarah di nagari kami ikut serta tetapi sering kami serahkan ke perangkat nagari atau jorong saja agar semua yang akan dibangun juga sejalan dengan rencana dari nagari. Dalam musyawarah nagari kami hanya mendengarkan saja apa yang di beri tahu oleh perangkat nagari. Kalau saya pribadi saya pernah ikut sekali dalam rapat itu, saya selaku masyarakat ikut serta dalam merembukkan. Setelah itu saya tidak pernah pergi atau ikut serta dalam rapat musyawarah lagi”. (Wawancara 09 September 2020).

Dari hasil wawancara tersebut dapat disimpulkan bahwa partisipasi masyarakat di Nagari Ladang Panjang masih kurang. Adapun masyarakat yang ikut dalam partisipasi musyawarah hanya mengikuti musyawarah sekali atau dua kali saja.

Berdasarkan hasil penelitian yang di temukan, proses pengambilan keputusan Nagari Ladang Panjang dilaksanakan melalui musyawarah rencana pembangunan nagari (musrenbang). Musrenbang adalah

59 | Jurnal Manajemen dan Ilmu Administrasi Publik | Volume 3 | Nomor 1 | Tahun 2021 | (Hal. 56-62) 
Rici Desriana Putri, Habullah Malau| Partisipasi Masyarakat Nagari dalam Meningkatkan Pembangunan Sarana dan Prasarana Nagari di Nagari Ladang Panjang Kabupaten Pasaman

forum musyawarah yang membahas usulanusulan rencana kegiatan pembangunan nagari yang berpedoman pada prinsipprinsip perencanaan pembangunan partisipasi masyaraakat nagari, serta transparasi pemerintah kepada masyarakat. Musyawarah yang dilaksanakan melibatkan semua stakeholder yang ada di nagari, seperti pemerintah nagari, Kerapatan Adat Nagari (KAN), Badan Perwakilan Rakyat Nagari (BPRN), lembaga unsur seperti ninik mamak, alim ulama, cadiak pandai, bundo kanduang, lembaga pemuda dan masyarakat nagari.

Partisipasi masyarakat dalam pembangunan sarana dan prasarana nagari di Nagari Ladang Panjang sudah terlaksana dengan baik walaupun hanya sebagian kecil masyarakat yang hanya berpartisipasi. Semua stakeholder yang ada di dalam nagari tersebut sudah merencanakan kebutuhan pembangunan nagari yang diwujudkan dalam proses pengambilan keputusan yang di awali dengan jenis sasaran hingga waktu pelaksanaan.

\section{Menentukan Kebutuhan yang Diinginkan}

Dalam menentukan kebutuhan yang diinginkan pemerintahan Nagari Ladang Panjang menentukan terlebih dahulu apa saja kebutuhan yang sangat perlu dalam sarana dan prasarana nagari dalam pembangunan Nagari Ladang Panjang. Seperti yang dijelaskan oleh Bapak Zulmadi selaku Sekna Nagari Ladang Panjang:

“...Suksesnya suatu pembangunan didukung oleh pendayagunaan atau manfaat dari sarana dan praasaranan yang ada di Nagari Ladang Panjang secara efektif dan efesien. Sarana dan prasarana sangat perlu dikelola demi lancarnya proses pembangunan dinagari. Contohnya saja untuk pembuatan kantor wali nagari yang harus ditentukan dulu apa saja sarana yang akan di perlukan, seperti lahan terlebih dahulu, ada juga tukang dari masyarakat itu sendiri yang mengikut sertakan dirinya sebagai bentuk partisipasi dari mereka". (Wawancara 10 September 2020).

Bapak Anton merupakan salah seorang warga masyarakat yang diwawancarai untuk mendengar tanggapannya sebagai perwakilan warga di tempat, berikut tanggapan tersebut:

“...Saya sendiri juga kadang tidak ikut berpartisipasi dalam hal pembangunan nagari. Ada kendala yang banyak dari saya peribadi seperti halnya saya kerja, jadi tidak sempat untuk ikut partisipasi apa lagi membantu dalam proses pendirian bangunan, apalagi pembangunan nagari tersebut sudah memiliki waktu selesainya atau sudah di tentukan kapan selesainya". (Wawancara 11 September 2020).

Dapat dilihat dari wawancara di atas bahwa partisipasi masyarakat pada Nagari Ladang Panjang memang masih kurang, dimana masyarakatnya lebih mengutamakan kepentingannya sendiri, ada beberapa hal dari kepentingan mereka yang tidak bisa ditunda.

Berdasarkan hasil penelitian yang ditemukan di lapangan, menentukan kebutuhan yang diinginkan untuk pembangunan adalah lahan untuk pendirian bangunan baru yaitu kantor wali nagarinya dimana masyarakat disini masih tidak ingin berpatisipasi dalam hal pembagian lahan sangat susah untuk membujuknya, sehingga perencanaan pembangunan bergerak lambat. Namun untuk saat sekarang ini pembangunan kantor wali nagari yang baru sudah bisa dikatakan dengan 50\% jadi. Karena hal ini terlihat dari penentuan kebutuhan yang dilakukan tidak menghasilkan pendapatan untuk nagari.

\section{Mewujudkan Tujuan dan Prioritas yang Ingin Dicapai}

Berdasarkan hasil temuan dilapangan dimana prioritas yang akan di wujudkan adalah hal penting dalam kenagarian, dimana masyarakatnya masih kurang berpartisipasi, bahkan setiap jorong pun 
Rici Desriana Putri, Habullah Malau| Partisipasi Masyarakat Nagari dalam Meningkatkan Pembangunan Sarana dan Prasarana Nagari di Nagari Ladang Panjang Kabupaten Pasaman

susah payah membujuk agar masyarakat mau memberikan sedikit lahan miliknya untuk pembuatan pembangunan nagari.

Faktor-faktor yang Menjadi Kendala dalam Partisipasi Masyarakat dalam Pembangunan Sarana dan Prasarana Nagari di Nagari Ladang Panjang

1. Masih Rendahnya Kualitas SDM dalam Mengelola Aset Nagari

Sumberdaya manusia adalah faktor pertama yang menjadi hambatan dalam melakukan pembangunan di Nagari Ladang Panjang. Kenyataan di lapangan menunjukkan bahwa sumber daya manusia yang memberikan lahan untuk pembangunan sarana dan prasarana nagari belum memberikan dengan seutuhnya, mereka masih dalam keraguan.

2. Minimnya Tingkat Kesadaran dan Partisipasi Masyarakat

Saat musyawarah nagari diadakan, pemerintah nagari berupaya dengan mengundang masyarakat untuk hadir dan berpartisipasi dalam menghadiri rapat sebagai salah satu pihak yang ikut mengelola aset nagari. Namun masyarakat sering tidak hadir untuk mengikuti rapat yang diadakan oleh pihak nagari.

Berdasarkan hasil wawancara dan temuan di lapangan menunjukkan kurangnya kesadaran masyarakat nagari tercemin dari sikap yang tidak mau berpartisipasi dalam pembangunan nagari dan selalu hanya mengikuti keputusan oleh perangkat nagari tanpa memberikan pendapatnya sendiri serta pengelolaan yang dilakukan hanya untuk kepentingan sendiri.

3. Sarana dan Prasarana Nagari yang Masih Belum Memadai

Dalam pembangunan sarana dan prasarana faktor ketiga yang menjadi kendala di Nagari Ladang Panjang adalah sumber daya dalam bentuk lahan yang belum ada dan peralatan yang kurang memadai. Sumber daya pelaratan merupakan sarana yang digunakan untuk operasionalisasi implementasi suatu kebijakan yang meliputi gedung, bangunan, tanah dan sarana yang semuanya akan memudahkan dalam memberikan pelayanan dalam implementasi kebijakan.

\section{Persoalan Anggaran}

Salah satu faktor yang menjadi kendala dalam melakukanpeningkatan dan perbaikan pembangunan bangunan baru atau kantor baru merupakan salah satu fakta dilapangan menunjukkan persoalan sumber anggaran. Terbatasnya anggaran dapat mempengaruhi implementasi tujuan perencanaan pembangunan sarana dan prasarana nagari ladang panjang yang sudah disusun sebelumnya. Sehingga sampai saat ini pembangunan kantor baru hanya berjalan setengahnya.

Sumber daya anggran merupakan sumber daya yang mempengaruhi implementasi setelah adanya sumber daya manusia, terbatasnya anggaran yang tersedia menyebabkan kualitas pelayanan terhadap publik yang harus diberikan kepada masyarakat juga terbatas.

\section{PENUTUP}

Partisipasi masyarakat dalam pembangunan sarana dan prasarana nagari di Nagari Ladang Panjangmasih kurang. Saat ini adapun partisipasi yang baru tampak dari masyarakat hanyalah bentuk pemberian lahan miliknya untuk pembangunan kantor wali nagari yang baru.

Kendala yang dihadapi dalam partisipasi masyarakat dalam pembangunan nagari untuk meningkatkan pembangunan secara tepat sasaran adalah: (a) masih rendahnya kualitas SDM dalam mengelola aset nagari, (b) minimnya tingkat kesadaran dan partisipasi masyarakat dan (c) kurangnya sarana dan prasarana dalam pembangunan.

Upaya yang dapat dilakukan mengatasi kendala yang dihadapi adalah: (a) melakukan sosialisasi dan pemberdayaan kepada masyarakat, (b) pemerintah nagari harus berusaha melakukan komunikasi dengan semua lembaga unsur dan tokoh 
Rici Desriana Putri, Habullah Malau| Partisipasi Masyarakat Nagari dalam Meningkatkan Pembangunan Sarana dan Prasarana Nagari di Nagari Ladang Panjang Kabupaten Pasaman

masyarakat yang ada dalam nagari untuk memaksimalkan pengelolaan aset.

Partisipasi masyarakat dalam pembangunan sarana dan prasarana nagari harus ditingkatkan lagi begitu juga dengan pemerintahan nagarinya harus giat melihat perkembangan masyarakatnya jangan hanya pembangunan saja, dimana masyarakat mungkin ingin lebih diperhatikan kembali baru ingin ikut berpartisipasi.

Pembangunan dalam bentuk pengambilan keputusan juga harus dipertimbangkan lagi karena semua keputusan yang diambil sendiri oleh pemerintahan nagari saja belum tentu di terima oleh seluruh masyarakat Nagari Ladang Panjang tersebut.

Pembangunan dalam bentuk mementukan kebututan yang diingin juga lebih diperhatikan lagi, sebaiknya dilaksanakan dengan dukungan warga setempat dan juga keikut sertaan masyarakat nagari tersebut.

Pemerintah nagari harus memaksimalkan terlebih dahulu tujuan dan prioritas yang ingin dicapai oleh nagari tersebut, begitu juga dengan masyarakatnya jangan terlalu mementingkan diri sendiri ataupun masalah pribadi.

\section{DAFTAR KEPUSTAKAAN}

Iskandar, K. (2009). Pemerintah Nagari Minangkabau dan Perkembangannya Tinjauan tentang Kerapatan Adat. Graha Ilmu.

Malau, H. (2018). Nilai-nilai Masyarakat Adat Nagari Kapau Kabupaten Agam dalam Perspektif Self-Governing Community. Teori Dan Praktek Administrasi Publik, II(2), 105.

Mustanir, A., \& Lubis, S. (2017). Participatory Rural Appraisal in Deliberations of Development Planning. 163(Icodag), 316-319. https://doi.org/10.2991/icodag-
17.2017.60

Nasional, D. P. (2007). Kamus Besar Bahasa Indonesia (ke-999). Gramedia Pustaka Utama.

Perda Kabupaten Pasaman Nomor 10 Tahun 2007 